\title{
ANALISIS PENGELOLAAN PENGANGKUTAN SAMPAH DI KECAMATAN ILIR TIMUR I KOTA PALEMBANG
}

\author{
Lega Reskita Lubis, ST. MT. ${ }^{1)}$ dan Zuul Fitriana Umari, ST. MT. ${ }^{2)}$ \\ ${ }^{1)}$ Teknik Sipil, Universitas Tridinanti, Palembang \\ ${ }^{2)}$ Teknik Sipil, Universitas Tridinanti, Palembang \\ Corresponding author: legalubis@univ-tridinanti.ac.id
}

\begin{abstract}
ABSTRAK:Kecenderungan jumlah pendudukdi Kecamatan Ilir Timur I Kota Palembang yang semakin meningkat serta diikuti kegiatan kota yang makin berkembang akan menimbulkan timbulan sampah yang meningkat. Timbulan sampah tersebut tentunya mempunyai dampak yang negatif terhadap lingkungan sekitarnya sehingga sangat diperlukan sistem pengelolaan persampahan yang memadai. Berdasarkan hasil pengamatan dilapangan dapat diketahui bahwa Dinas Kebersihan Kota Palembangmasih belum dapat mengatasi timbulan sampah. Hal ini terbukti dengan banyaknya timbulan sampah di Kecamatan Ilir Timur I Kota Palembang sehingga terganggu terhadap estetika. Hasil dari penelitian ini didapatkan besarnya laju timbulan sampah di Kecamatan Ilir Timur I Kota Palembang yang akan dapat memberikan informasi bagi Dinas Kebersihan Kota Palembangdalam kaitannya meningkatkan pengelolaan sampah yang berkelanjutan.
\end{abstract}

Kata Kunci:Persampahan, Timbulan Sampah, Pengelolaan Sampah

\section{PENDAHULUAN}

Pertambahan jumlah penduduk merupakan faktor utama terjadinya permasalahan sampah karena manusia merupakan penghasil utama sampah.Pertambahan jumlah penduduk yang tidak di imbangi dengan dengan pengelolaan sampah yang baik akan menyebabkan bertambahnya tumpukan sampah di berbagai tempat.

Penumpukan sampah tersebut tentunya mempunyai dampak yang negatif terhadap lingkungan sekitarnya. Sehinggasangat diperlukan sistem pengelolaan persampahan yang memadai. Pelaksanaan pengelolaan persampahan sangat dipengaruhi komponenkomponen yang mendukung yaitu aspek teknis, kelembagaan, hukum atau peraturan, pembiayaan maupun peran serta masyarakat.

Permasalahan sampah timbul akibat pengelolaan sampah yang tidak dilakukan dengan baik yaitu sistem pengumpulan yang tidak tuntas, kurangnya alat angkut dan terbatasnya kapasitas tempat pembuangan akhir sampah (TPA) menurut Pramono.

\section{LANDASAN TEORI}

Pengertian Sampah

Menurut Undang-Undang Nomor 18 Tahun 2008 tentang Pengelolaan Sampah, sampah adalah sisa kegiatan sehari-hari manusia dan atau proses alam yang berbentuk padat. Kemudian yang dimaksud dengan sampah 
spesifik adalah sampahyang karena sifat, konsentrasi, dan atau volumenya memerlukan pengelolaan khusus. Sedangkan menurut Hadiwiyoto (1983:12), sampah adalah bahan sisa, baik bahan-bahan yang sudah tidak digunakan lagi (barang bekas) maupun bahan yang sudah diambil bagian utamanya yang dari segi ekonomis, sampah adalah bahan buangan yang tidak ada harganya dan dari segi lingkungan, sampah adalah bahan buangan yang tidak berguna dan banyak menimbulkan masalah pencemaran dan gangguan pada kelestarian lingkungan.

Banyak lagi ahli yang mengajukan batasanbatasan lain, tapi pada umumnya mengandung prinsip-prinsip yang sama, (Haryoto Kusno Saputro, 1983), yaitu:

a. Adanya suatu benda atau zat padat atau bahan

b. Berhubungan langsung atau tidak langsung denganaktivitas manusia.

c. Bahan atau benda tak terpakai, tidak disenangi dan dibuang dengan cara-cara yang diterima (perlu pengelolaan yang baik).

\section{Sumber Sampah}

Menurut SNI 19-3983-1995, sumber sampah berasal dari:

a. Perumahan; rumah permanen, rumah semi permanen, rumah non permanen.

b. Non perumahan; kantor, toko atau ruko, pasar, sekolah, tempat ibadah, jalan, hotel, restoran, industri, rumah sakit, dan fasilitas umum lainnya.
Tabel Besarnya Timbulan Sampah Berdasarkan Sumbernya

\begin{tabular}{|c|l|c|c|c|}
\hline No. & $\begin{array}{l}\text { Komponen Sumber } \\
\text { Sampah }\end{array}$ & Satuan & $\begin{array}{c}\text { Volume } \\
\text { (litter) }\end{array}$ & $\begin{array}{c}\text { Berat } \\
(\mathrm{Kg})\end{array}$ \\
\hline 1. & Rumah Permanen & /orang/hari & $2,25-2,50$ & $0,350-0,400$ \\
\hline 2. & $\begin{array}{l}\text { Rumah Semi } \\
\text { Permanen }\end{array}$ & /orang/hari & $2,00-2,25$ & $0,300-0,350$ \\
\hline 3. & $\begin{array}{l}\text { Rumah Non } \\
\text { Permanen }\end{array}$ & /orang/hari & $1,75-2,00$ & $0,250-0,300$ \\
\hline 4. & Kantor & /pegawai/hari & $0,50-0,75$ & $0,250-0,100$ \\
\hline 5. & Toko / Ruko & /pegawai/hari & $2,50-3,00$ & $0,150-0,350$ \\
\hline 6. & Sekolah & $/$ murid/hari & $0,10-0,15$ & $0,010-0,020$ \\
\hline 7. & Jalan Arteri Sekunder & $/ \mathrm{m} /$ hari & $0,10-0,15$ & $0,020-0,100$ \\
\hline 8. & $\begin{array}{l}\text { Jalan Kolektor } \\
\text { Sekunder }\end{array}$ & $/ \mathrm{m} /$ hari & $0,10-0,15$ & $0,010-0,050$ \\
\hline 9. & Jalan Lokal & $/ \mathrm{m} /$ hari & $0,05-0,10$ & $0,005-0,025$ \\
\hline 10. & Pasar & $/ \mathrm{m}^{2} /$ hari & $0,20-0,60$ & $0,100-0,300$ \\
\hline
\end{tabular}

\section{Teknik Operasional}

Teknik Operasional terbagi menjadi pewadahan sampah, pengumpulan sampah, pemindahan sampah dan pengangkutan sampah.

Tabel 2.5 Karakteristik Wadah Sampah

\begin{tabular}{|c|c|l|l|}
\hline No. & Pola Pewadahan & \multicolumn{1}{|c|}{ Individual } & \multicolumn{1}{|c|}{ Komunal } \\
\hline 1. & Karakteristik & $\begin{array}{l}\text { Kotak, silinder, } \\
\text { kontainer, bin (tong), } \\
\text { semua bertutup dan } \\
\text { kantong plastik. }\end{array}$ & $\begin{array}{l}\text { Kotak, silinder, } \\
\text { kontainer, bin (tong), } \\
\text { semua bertutup. }\end{array}$ \\
\hline 2. & Sifat & $\begin{array}{l}\text { Ringan mudah } \\
\text { dipindahkan dan } \\
\text { mudah dikosongkan. }\end{array}$ & $\begin{array}{l}\text { Ringan, mudah } \\
\text { dipindahkan dan } \\
\text { mudah dikosongkan. }\end{array}$ \\
\hline 3. & Jenis & $\begin{array}{l}\text { Logam, plastik, } \\
\text { fiberglas (GRP), kayu, } \\
\text { bambu, rotan. }\end{array}$ & $\begin{array}{l}\text { Logam, plastik, } \\
\text { fiberglas (GRP), } \\
\text { kayu, } \\
\text { bambu, rotan. }\end{array}$ \\
\hline 4. & Pengadaan & $\begin{array}{l}\text { Pribadi, instansi, } \\
\text { pengelola }\end{array}$ & Instansi pengelola \\
\hline
\end{tabular}

Dari tabel diatas dapat dilihat karakteristik pola pewadahan sampah individual dan komunal.

Tabel Pewadahan dan Kapasitasnya

\begin{tabular}{|l|l|l|l|l|l|}
\hline No. & \multicolumn{1}{|c|}{ Wadah } & Kapasitas & Pelayanan & $\begin{array}{l}\text { Umur wadah/ } \\
\text { life time }\end{array}$ & \multicolumn{1}{|c|}{ Keterangan } \\
\hline 1. & Kantong Plastik & $10-40 \mathrm{~L}$ & $1 \mathrm{KK}$ & $2-3$ hari & Individual \\
\hline 2. & Tong & $40 \mathrm{~L}$ & $1 \mathrm{KK}$ & $2-3$ hari & Max 3 hari 1x \\
\hline 3. & Tong & $120 \mathrm{~L}$ & $2-3 \mathrm{KK}$ & $2-3$ hari & Toko \\
\hline 4. & Tong & $140 \mathrm{~L}$ & $4-6 \mathrm{KK}$ & $2-3$ hari & \\
\hline 5. & Kontainer & $1000 \mathrm{~L}$ & $80 \mathrm{KK}$ & $2-3$ hari & Komunal \\
\hline 6. & Kontainer & $500 \mathrm{~L}$ & $40 \mathrm{KK}$ & $2-3$ hari & Komunal \\
\hline 7. & Tong & $30-40 \mathrm{~L}$ & $\begin{array}{l}\text { Pejalan } \\
\text { kaki, taman }\end{array}$ & $2-3$ hari & \\
\hline
\end{tabular}

Dari tabel diatas dapat diketahui wadah sampah dengan kapasitasnya. 


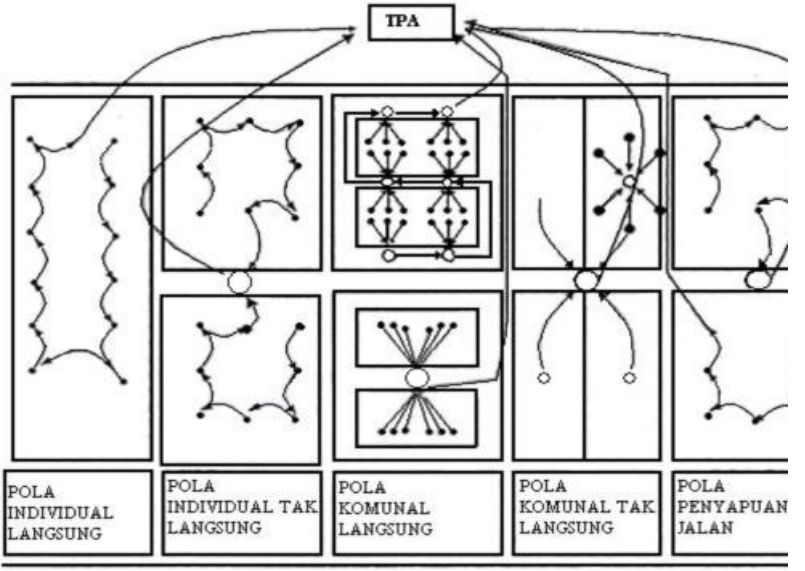

Dari gambar diatas dapat diketahui berbagai pola pengumpulan sampah.

Perencanaan Operasional Pengumpulan

Perencanaan operasional pengumpulan sebagai berikut:

1. Rotasi antar $1-4 /$ hari

2. Periodisasi: 1 hari, 2 hari, atau maksimal 3 hari sekali, tergantung dari kondisi komposisi sampah, yaitu:

a. Semakin besar prosentasi sampah organik, periodisasi pelayanan maksimal sehari 1 kali

b. Untuk sampah kering, periode pengumpulannya disesuaikan dengan jadwal yang telah ditentukan, dapat dilakukan lebih dari 3 hari 1 kali

c. Untuk sampah B3 disesuaikan dengan ketentuan yang berlaku

d. Mempunyai daerah pelayanan tertentu dan tetap

e. Mempunyai petugas pelaksa yang tetap dan dipindahkan secara periodik

f. Pembebanan pekerjaan diusahakan merata dengan kriteria jumlah sampah terangkut, jarak tempuh, dan kondisi daerah.
Pelaksana pengumpulan sampah

Pengumpulan sampah dapat dilaksanakan oleh:

1) Institusi kebersihan kota

2) Lembaga swadaya masyarakat

3) Swasta

4) Masyarakat (oleh RT/RW).

Jenis sampah yang terpilah dan bernilai ekonomi dapat dikumpulkan oleh pihak yang berwenang pada waktu yang telah disepakati bersama antara petugas pengumpul dan masyarakat penghasil sampah.

\section{Pemindahan sampah}

Tipe pemindahan sampah dapat dilihat pada tabel dibawah ini.

Tabel Tipe Pemindahan (Transfer)

\begin{tabular}{|c|c|c|c|c|}
\hline No. & Uraian & $\begin{array}{c}\text { Tranfer Depo } \\
\text { Tipe I }\end{array}$ & $\begin{array}{c}\text { Transfer Depo } \\
\text { Tipe II }\end{array}$ & $\begin{array}{c}\text { Transfer Depo } \\
\text { Tipe III }\end{array}$ \\
\hline 1. & Luas Lahan & $>200 \mathrm{~m}^{2}$ & $>60 \mathrm{~m}^{2}$ & $10-20 \mathrm{~m}^{2}$ \\
\hline 2. & Fungsi & \begin{tabular}{|c|} 
- Tempat \\
pertemuan \\
peralatan \\
pengumpulan dan \\
pengangkutan \\
sebelum \\
pemindahan \\
- Tempat \\
penyimpanan atau \\
kebersihan \\
- Bengkel \\
sederhana \\
- Kantor \\
wilayah/pengendali \\
- Tempat \\
pemilahan \\
- Tempat \\
pengomposan
\end{tabular} & $\begin{array}{c}\text { - Tempat } \\
\text { pertemuan } \\
\text { peralatan } \\
\text { pengumpul } \\
\text { dan } \\
\text { pengangkutan } \\
\text { sebelum } \\
\text { pemindahan } \\
\text { - Tempat } \\
\text { parker gerobak } \\
\text {-Tempat } \\
\text { pemilahan }\end{array}$ & $\begin{array}{c}\text { - Tempat } \\
\text { pertemuan } \\
\text { gerobak dan } \\
\text { kontainer }(6-10 \\
\text { m3) } \\
\text { - Lokasi } \\
\text { penempatan } \\
\text { kontainer } \\
\text { komunal }(1- \\
10 \mathrm{~m} 3)\end{array}$ \\
\hline 3. & $\begin{array}{l}\text { Daerah } \\
\text { Pemakai }\end{array}$ & $\mid \begin{array}{c}\text { - Baik sekali untuk } \\
\text { daerah yang mudah } \\
\text { mendapat lahan }\end{array}$ & & $\begin{array}{c}\text { - Daerah } \\
\text { yangsulit } \\
\text { mendapat } \\
\text { lahan yang } \\
\text { kosong dan } \\
\text { daerah } \\
\text { protokol }\end{array}$ \\
\hline
\end{tabular}

Konsep Pengelolaan Sampah Terpadu 3R

(Reduce, Reuse, Recycle) 
Konsep 3R adalah paradigma baru dalam pola konsumsi dan produksi disemua tingkatan dengan memberikan prioritas tertinggi pada pengelolaan limbah yang berorientasi pada pencegahan timbulan sampah, minimalisasi limbah dengan mendorong barang yang dapat digunakan lagi dan barang yang dapat didekomposisi secara biologi (biodegradable) dan penerapan pembuangan limbah yang ramah lingkungan.

Pelaksanaan 3R tidak hanya menyangkut masalah sosial dalam rangka mendorong perubahan sikap dan pola pikir menuju terwujudnya masyarakat yang ramah lingkungan dan berkelanjutan tetapi juga menyangkut pengaturan (manajemen) yang tepat dalam pelaksanaannya. (PU Cipta Karya, 2011).

\section{METODOLOGI PENELITIAN}

Tahap Pengumpulan Data

Pengumpulan data dilakukan dengan pengamatan langsung (survey).

1. Survey lokasi untuk mendapatkan data data awal tentang bagaimana kondisi TPS saat ini di kawasan Ilir Timur I Kota

Palembang yang meliputi: kelayakan TPS dan armada pengangkut sampah.

2. Data jumlah penduduk di kawasan Ilir Timur I Kota Palembang.

Tahapan Pengolahan Data dan Analisis

1. Menganalisis timbulan sampah yang dihasilkanKecamatan Ilir Timur I Kota Palembang.
2. Menganalisis kebutuhan alat pengangkutan sampah dalam perencanaan sarana dan prasarana persampahan di Kecamatan Ilir Timur I Kota Palembang.

\section{HASIL PENELITIAN DAN PEMBAHASAN}

\section{Proyeksi Jumlah Penduduk}

Jumlah penduduk Kecamatan Ilir Timur I pada tahun 2017 dan 2018 yang dari Badan Pusat Statistik Kota Palembang dapat dilihat pada tabel dibawah ini:

Perhitungan proyeksi pertumbuhan penduduk menggunakan metode perhitungan linear dengan cara geometrik. Prediksi jumlah pendudukdiperoleh denganterlebih dahulu mencari nilai laju pertumbuhan penduduk (r) pada kelurahan, 18 Ilir, 20 Ilir I, 20 Ilir III, 20 Ilir IV, Kepandean Baru dan Sungai Pangeran. Laju Pertumbuhan Penduduk Kecamatan Ilir Timur Itersaji pada tabel dibawah ini:

Tabel Laju Pertumbuhan Penduduk Kecamatan Ilir Timur I

\begin{tabular}{|c|c|c|c|c|}
\hline \multirow{2}{*}{ No } & \multirow{2}{*}{ Kelurahan } & \multicolumn{2}{|c|}{$\begin{array}{l}\text { Jumlah Penduduk } \\
\text { Pada Tahun }\end{array}$} & \multirow{2}{*}{$\begin{array}{c}\mathrm{r} \\
(\%)\end{array}$} \\
\hline & & $\begin{array}{c}2017 \\
\text { (Jiwa) }\end{array}$ & $\begin{array}{c}2018 \\
\text { (Jiwa) }\end{array}$ & \\
\hline 1. & 18 Ilir & 2.223 & 2.368 & 0.07 \\
\hline 2. & 20 Ilir I & 12.217 & 13.012 & 0.07 \\
\hline 3. & 20 Ilir III & 10.846 & 11.549 & 0.06 \\
\hline 4. & 20 Ilir IV & 15.962 & 17.002 & 0.07 \\
\hline 5. & Kepandean Baru & 2.114 & 2.249 & 0.06 \\
\hline 6. & Sungai Pangeran & 11.139 & 11.863 & 0.06 \\
\hline
\end{tabular}


Pada tabel diatas diketahui laju pertumbuhan penduduk Kecamatan Ilir Timur I pada kelurahan. Tingkat laju pertumbuhan penduduk Kelurahan 20 Ilir III, Kepandean Baru, dan Sungai Pangeran adalah sebesar $0,06 \%$. Tingkat laju pertumbuhan penduduk kelurahan 18 Ilir, dan 20 Ilir I dan 20 Ilir IV, mencapai 0,07\%.

Proyeksi jumlah penduduk dilakukan untuk lima tahun kedepan. Hasil proyeksi jumlah penduduk dari 2019 sampai 2024 dapat diihat pada tabel dibawah ini:

Tabel Proyeksi Jumlah Penduduk Kecamatan Ilir Timur I

\begin{tabular}{|c|l|c|c|c|c|c|c|}
\hline \multirow{2}{*}{ No. } & \multirow{2}{*}{ Kelurahan } & \multicolumn{6}{|c|}{ Jumlah Penduduk Pada Tahun } \\
\cline { 3 - 8 } & & $\begin{array}{r}2019 \\
\text { (Jiwa) }\end{array}$ & $\begin{array}{r}2020 \\
\text { (Jiwa) }\end{array}$ & $\begin{array}{r}2021 \\
\text { (Jiwa) }\end{array}$ & $\begin{array}{r}2022 \\
\text { (Jiwa) }\end{array}$ & $\begin{array}{r}2023 \\
\text { (Jiwa) }\end{array}$ & $\begin{array}{c}2024 \\
\text { (Jiwa) }\end{array}$ \\
\hline 1. & 18 Ilir & 2522 & 2687 & 2862 & 3049 & 3248 & 3460 \\
\hline 2. & 20 Ilir I & 13859 & 14761 & 15721 & 16744 & 17834 & 18994 \\
\hline 3. & 20 Ilir III & 12298 & 13095 & 13943 & 14847 & 15810 & 16834 \\
\hline 4. & 20 Ilir IV & 18110 & 19290 & 20547 & 21885 & 23311 & 24830 \\
\hline 5. & Kepandean Baru & 2393 & 2545 & 2708 & 2881 & 3065 & 3261 \\
\hline 6. & Sungai Pangeran & 12634 & 13455 & 14330 & 15261 & 16253 & 17309 \\
\hline
\end{tabular}

Dari tabel diatas dapat diketahui proyeksi jumlah penduduk Kecamatan Ilir Timur I sampai dengan tahun 2024.

Berdasarkan klasifikasi diatas besaran timbulan sampah wilayah studi, untuk wilayah dengan jumlah penduduk $<100.000$ adalah 2,52,75 Ltr/org/hari. Dan perhitungan dilakukan dengan mengalihkan standar besaran timbulan sampah yang diperoleh secara bertahap dari tahun 2019 sampai tahun 2024, dengan besaran timbulan sampah 2,75 Ltr/org/hari. Proyeksi timbulan sampah dapat dilihat pada
TabelProyeksi timbulan sampah dalam liter/hari dikonversikan $\mathrm{ke}^{3} /$ hari.

Tabel Proyeksi Besaran Timbulan Sampah Kecamatan Ilir Timur I

\begin{tabular}{|c|c|c|c|c|c|c|c|}
\hline \multirow{2}{*}{$\begin{array}{l}\mathrm{N} \\
\mathrm{o} .\end{array}$} & \multirow{2}{*}{ Kelurahan } & \multicolumn{6}{|c|}{ Volume Timbulan Sampah } \\
\hline & & $\begin{array}{c}2019 \\
\left(\mathrm{~m}^{3} / \mathrm{har}\right)\end{array}$ & $\begin{array}{c}2020 \\
\left(\mathrm{~m}^{3} / \mathrm{hari}\right)\end{array}$ & $\begin{array}{c}2021 \\
\left(\mathrm{~m}^{3} / \text { hari }\right)\end{array}$ & $\begin{array}{c}2022 \\
\left(\mathrm{~m}^{3} / \mathrm{hari}\right)\end{array}$ & $\begin{array}{c}2023 \\
\left(\mathrm{~m}^{3} / \mathrm{hari}\right)\end{array}$ & $\begin{array}{r}2024 \\
\left(\mathrm{~m}^{3} / \text { hari }\right.\end{array}$ \\
\hline 1. & $18 \mathrm{Ilir}$ & 6.113 & 6.512 & 6.937 & 7.389 & 7.871 & 8.385 \\
\hline 2. & 20 Ilir I & 33.597 & 35.783 & 38.112 & 40.592 & 43.233 & 46.046 \\
\hline 3. & 20 Ilir IIII & 29.827 & 31.760 & 33.818 & 36.010 & 38.344 & 40.830 \\
\hline 4. & 20 Ilir IV & 43.896 & 46.756 & 49.802 & 53.047 & 56.503 & 60.184 \\
\hline 5. & $\begin{array}{r}\text { Kepandean } \\
\text { Baru }\end{array}$ & 5.814 & 6.185 & 6.580 & 7.000 & 7.447 & 7.922 \\
\hline 6. & SungaiPangeran & 30.632 & 32.623 & 34.744 & 37.002 & 39.407 & 41.968 \\
\hline
\end{tabular}

Tabel diatas menunjukanvolume timbulan sampah prediksi di Kecamatan Ilir Timur I. Kelurahan 20 Ilir IV memiliki volume timbulan sampah yang terbesar, hal ini dikarenakan kelurahan 20 Ilir IV memiliki jumlah penduduk terbanyak pula.

Jumlah armada sampah yang ada di Kecamatan Ilir Timur I mempunyai 7 armada sampah. Armada sampah berfungsi untuk mengangkut timbulan sampah dari Tempat Pembuangan Sementara ke Tempat Pembuangan Akhir. Perhitungan kebutuhan armada angkutan sampah/Dump Truck di Kecamatan Ilir Timur I Kota Palembang tahun 2024 sebanyak 15 unit dapat dilihat pada tabel 4.5 dibawah ini :

Tabel Kebutuhan Dump Truk di Kecamatan Ilir Timur I Tahun 2024 


\begin{tabular}{|c|c|c|c|c|c|}
\hline No & Kelurahan & $\begin{array}{c}\text { Jumlah } \\
\text { pendud } \\
\text { uk } \\
2024 \\
\text { ( Jiwa ) }\end{array}$ & $\begin{array}{l}\text { Vol . } \\
\text { Timbulan } \\
\text { Sampah } \\
\text { (m3/Hari) }\end{array}$ & $\begin{array}{l}\text { Rute } \\
\text { Trip/ } \\
\text { Hari }\end{array}$ & $\begin{array}{c}\text { Dump } \\
\text { Truck } \\
\text { yang } \\
\text { dibutuh } \\
\text { kan } \\
\text { ( unit ) }\end{array}$ \\
\hline 1. & 18 Ilir & 3460 & 8.385 & 2 & 1 \\
\hline 2. & 20 Ilir I & 18994 & 46.046 & 2 & 3 \\
\hline 3. & 20 Ilir III & 16834 & 40.830 & 2 & 3 \\
\hline 4. & 20 Ilir IV & 24830 & 60.184 & 2 & 4 \\
\hline 5. & Kepandean Baru & 3261 & 7.922 & 2 & 1 \\
\hline 6. & Sungai Pangeran & 17309 & 41.968 & 2 & 3 \\
\hline & Jumlah & \multicolumn{4}{|c|}{15} \\
\hline
\end{tabular}

Pada Tabel 4.5 didapatkan jumlah armada sampah pada tahun 2024 diperlukan adalah sebesar 15 unit armada sampah.

\section{KESIMPULAN}

Berdasarkan analisis perhitungan dan perencanaan yang dilakukan, maka dapat diambil beberapa kesimpulan sebagai berikut :

1. Estimasi volume sampah pada Kecamatan Ilir Timur I Kota Palembang pada tahun 2019 adalah sebesar $169.991 \mathrm{~m} 3 /$ hari dengan penduduk 61.816 jiwa dan pada tahun 2024 estimasi timbulan sampahnya sebesar $232.892 \mathrm{~m} 3 /$ hari dengan jumlah penduduk 84.688 jiwa yang terdiri dari 6 kelurahan.

2. Kebutuhan jumlah armada sampah pada Kecamatan Ilir Timur I Kota Palembang pada tahun 2019 adalah sebesar 9 unit armada dan pada tahun 2024 meningkat sebesar 4 unit armada sehingga menjadi 15 unit armada sampah an dua kali trip pengangkutan sampah.

3. Sistem pengangkutan direncanakan pada tahun 2024 dengan menggunakan pola Stationary Container System ( SCS ) yang merupakan sistem pengumpulan sampah yang wadah pengumpulannya tidak dibawa berpindah-pindah (tetap).

\section{DAFTAR PUSTAKA}

Anonim, 2002. Tata Cara Teknik Operasional Pengelolaan Sampah Perkotaan (SNI 192454-2002). Badan Standarisasi Nasional, Jakarta.

Damanhuri, E., Tri Padmi, Azhar, N., Meilany, L. T., (1989), Pengkajian Laju Timbunan Sampah di Indonesia, Pus. Lit. Bang.

Pemukiman Dept PU - LPM ITB,Bandung. Damanhuri, E., Pengelolaan Sampah. Program Studi T. LingkunganFTSL ITB, Bandung, 2004.

DKP, Profil Dinas Kebersihan kota Palembang 2008. Kota Palembang, Palembang, 2008. Nadiasa,N.,Dewa Ketut Sudarsana,I Nyoman Yasmara, ( 2009 ), Manajemen

Pengangkutan Sampah Di Kota Amlapura, Jurnal, Jurusan Teknik Sipil Universitas Udayana, Denpasar. 